\title{
Interferon regulatory factor-7 modulates experimental autoimmune encephalomyelitis in mice
}

\author{
Mohammad Salem ${ }^{\dagger}$, Jyothi T Mony ${ }^{\dagger}$, Morten Løbner, Reza Khorooshi ${ }^{*}$ and Trevor Owens
}

\begin{abstract}
Background: Multiple sclerosis (MS) is an inflammatory disease of the central nervous system (CNS) with unknown etiology. Interferon- $\beta$ (IFN- $\beta$ ), a member of the type I IFN family, is used as a therapeutic for MS and the IFN signaling pathway is implicated in MS susceptibility. Interferon regulatory factor 7 (IRF7) is critical for the induction and positive feedback regulation of type I IFN. To establish whether and how endogenous type I IFN signaling contributes to disease modulation and to better understand the underlying mechanism, we examined the role of IRF7 in the development of MS-like disease in mice.

Methods: The role of IRF7 in development of EAE was studied by immunizing IRF7-KO and C57BL/6 (WT) mice with myelin oligodendrocyte glycoprotein using a standard protocol for the induction of EAE. We measured leukocyte infiltration and localization in the CNS using flow cytometric analysis and immunohistochemical procedures. We determined levels of CD3 and selected chemokine and cytokine gene expression by quantitative real-time PCR.

Results: IRF7 gene expression increased in the CNS as disease progressed. IRF7 message was localized to microglia and infiltrating leukocytes. Furthermore, IRF7-deficient mice developed more severe disease. Flow cytometric analysis showed that the extent of leukocyte infiltration into the CNS was higher in IRF7-deficient mice with significantly higher number of infiltrating macrophages and T cells, and the distribution of infiltrates within the spinal cord was altered. Analysis of cytokine and chemokine gene expression by quantitative real-time PCR showed significantly greater increases in CCL2, CXCL10, IL-1 $\beta$ and IL17 gene expression in IRF7-deficient mice compared with WT mice.
\end{abstract}

Conclusion: Together, our findings suggest that IRF7 signaling is critical for regulation of inflammatory responses in the CNS.

Keywords: IRF7, type I IFN, EAE, inflammation, central nervous system, chemokines, cytokines

\section{Background}

Multiple sclerosis (MS) is a chronic inflammatory demyelinating disease of the central nervous system (CNS), which is likely triggered by infection or other environmental events $[1,2]$. Experimental autoimmune encephalomyelitis (EAE) is an animal model for MS that is induced by immunization with myelin antigens [3]. In

\footnotetext{
* Correspondence: Rkhorooshi@health.sdu.dk

† Contributed equally

Department of Neurobiology Research, Institute of Molecular Medicine, University of Southern Denmark, Odense, Denmark
}

both MS and EAE demyelinating lesions are accompanied by $\mathrm{T}$ cell and macrophage infiltration $[2,3]$.

The first clinically approved therapy for MS was IFN$\beta[4,5]$, a member of the type I IFN family that also includes multiple IFN- $\alpha$ subtypes. Type I IFNs are classically induced by viral infection and act through a common receptor, IFNAR [6]. The transcription factor IRF7 is constitutively expressed at low levels in the cytoplasm $[7,8]$, and becomes activated by innate receptor signaling, resulting in translocation to the nucleus and induction of type I IFN [9]. Type I IFN signaling leads to further induction of IRF7, so creating a feed-forward

\section{() Biomed Central}


loop to amplify production of type I IFN. IRF7 may therefore represent a link between innate receptor and type I IFN signaling. Consequently, changes in IRF7 function may affect processes regulated by type I IFN. Mice lacking IRF7 are deficient in type I IFN responses and consequently lack innate responsiveness to viruses $[10,11]$.

In addition to their antiviral function, type I IFNs play a critical role in the regulation of inflammation in the CNS [12]. Mice lacking either IFN $\beta$ or IFNAR develop more severe EAE, with increased CNS infiltration [13-15]. Recent evidence suggests that type I IFN may be produced within the CNS, in response to inflammation or injury, and that signaling through IFNAR modulates leukocyte infiltration $[7,8,16]$. We have shown that synaptic degeneration-induced IRF7 increase in the CNS is IFNAR-dependent [8].

The signaling pathways mediating production and effect of type I IFN in the CNS remain uncertain. Here we analyze the role of IRF7 in EAE, and show that mice lacking this transcription factor develop more severe EAE, with increased CNS infiltration. This implicates IRF7 as a key signaling intermediate in modulation of autoimmune demyelinating disease. Due to its regulatory action on type I IFN signaling, IRF7 therefore represents an important factor that regulates development of CNS autoimmune diseases, such as MS.

\section{Materials and methods}

\section{Animals}

IRF7-KO mice on C57BL/6 (B6) background were purchased from Riken BioResource Center (Tsukuba, Japan) and maintained as a breeding colony. Control wild-type B6 mice, which have been shown to be appropriate controls for EAE studies [17], were obtained from Taconic (RY, Denmark). Mice were provided with food and water ad libitum. All experiments were approved by the Danish Justice Ministry Committee on Animal Research (Approval Number 2009/561-1724).

\section{Induction of EAE and Clinical Evaluation}

To induce EAE, adult female IRF7-KO and control B6 mice were subcutaneously immunized with 35-55 myelin oligodendrocyte glycoprotein (35-33 MOG) peptide in complete Freund's adjuvant containing $2 \mathrm{mg} / \mathrm{ml} M$. tubercolosis in the flanks. In addition, mice received intraperitoneal injections with $200 \mu \mathrm{l}$ pertussis toxin $(1,5$ $\mu \mathrm{g} / \mathrm{ml}$ ) (Sigma-Aldrich, Brøndby, Denmark) at the time of immunization and two days later. Mice were then caged in groups of 8 (4 WT mice with 4 IRF7-KO mice). The mice were weighed and monitored daily for clinical signs of EAE, which were scored as follows: 0, no symptoms; 1, Weak or hooked tail; 2, Floppy tail; 3, $2+$ hind limb paresis (weak hind limbs-assessed by the animal's slowness or splaying limbs when walking or unsteady walk in the cage or on the lid of the cage), Grade 4: 3 + very weak hind limbs or one hind limb paralysed- hind limb paresis-assessed by the animal dragging one or both hind limbs (not complete loss of tonus in one or both hind limbs); $5,4+$ unilateral hind limb paralysis (both hind limbs paralysed); 6, $5+$ paresis in one forelimb. Because of ethical reasons, mice were euthanized when they reached a clinical score of 5 . In the first experiment the clinical score in first euthanized 4 mice was 3-4, and all other euthanized mice had clinical score 5. At the end of experiment all remaining mice were euthanized. In the second and third experiment, half of the mice were sacrificed at day 15 and the rest either when they scored 4-5 or at the end of experiment. Mice were weighed and scored in a blinded manner.

\section{Tissue preparation}

Mice were deeply anaesthetized and perfused intracardially with ice-cold Phosphate Buffered Saline (PBS). Spinal cords were dissected out and processed as followed:

For Histology: the tissues were placed in $4 \%$ paraformaldehyde (PFA) (Sigma-Aldrich) for 60 minutes and overnight in $1 \%$ PFA at $4^{\circ} \mathrm{C}$. The tissues were then placed in $20 \%$ sucrose solution overnight, freezeembedded in cryo-embedding (Ax-lab, Vedbæk, Denmark), cut in 16- $\mu \mathrm{m}$ cryostat sections, mounted on glass slides and stored at $-80^{\circ} \mathrm{C}$.

For Flow Cytometry: the tissues were placed in a plate with Hanks Balanced Salt Solution (HBSS) (Invitrogen A/S, Taastrup, Denmark) for further processing.

For Quantitative real-time reverse transcriptase- PCR assay: the tissues were placed in eppendorf tubes containing TRIzol (Invitrogen Life Technologies, Paisley, Scotland, UK), which were then stored in $-80^{\circ} \mathrm{C}$ until further processing.

\section{Histology}

To investigate the extent and distribution of histopathology Hematoxylin and Eosin staining was performed. Double Immunostaining was used to detect astrocytes and T-cells. In brief, sections were washed in PBS, followed by rinsing in PBS- $0.5 \%$ Triton (Triton- X-100) (Sigma-Aldrich) (PBST) and blocked in a solution containing PBST and 3\% BSA (Sigma-Aldrich). Thereafter, sections were incubated with $\mathrm{Cy}-3$ conjugated mouse anti GFAP antibody (C9205, Sigma-Aldrich), and Rat anti-mouse CD3 (MCA500G, Serotec) antibodies, in order to detect astrocytes and $\mathrm{T}$ cells respectively. After several washes in PBST, sections were incubated with donkey anti-rat Alexa Fluor-488 antibody (InvitrogenMolecular Probes, Taastrup, Denmark), to visualize antiCD3 antibody. Nuclei were then stained with DAPI 
(Invitrogen-Molecular Probes). To test the specificity of staining, control sections were treated without primary antibody or with isotype-matched primary antibodies. Control sections displayed no staining comparable with that seen without primary antibodies (not shown). Images were acquired using an Olympus BX51 microscope (Olympus, Denmark) connected to an Olympus DP71 digital camera, and combined using Adobe Photoshop CS version 8.0 to visualize double-labeled cells.

\section{Flow cytometry}

Single cell suspensions of spinal cords and lymph nodes (LN) were prepared by dissociation using a $70 \mu \mathrm{m}$ cell strainer (BD Biosciences, Brøndby, Denmark). Spinal cord samples were resuspended in 37\% Percoll (GE Healthcare Bio-sciences AB, Uppsala, Sweden) and centrifuged to remove myelin. Blocking was performed using Mouse Fc Block (BD Biosciences). Cells were stained with biotinylated anti-mouse CD8, FITC anti-mouse CD4 or PerCP/Cy5.5 anti-mouse CD11b and phycoerythrin (PE) anti-mouse CD45 (BD Biosciences). Data was collected on a FACS Calibur (BD Biosciences), and analyzed using Flowjo software (Tree Star, Ashland, OR).

\section{T cell stimulation and intracellular cytokine staining}

Single cell suspensions prepared as described above were plated in 96 well plates coated with anti-mouse CD3E (145-2C11) and cultured for 9 hours to stimulate cytokine production in T cells. GolgiPlug (BD Biosciences) was added two hours after plating. After incubation, cells were washed and stained with V500-rat anti mouse CD4 (BD), PerCP/Cy5.5 anti-mouse CD $8 \alpha$ (Biolegend) and either allophycocyanin (APC)-anti-mouse CD196 (CCR6) (Biolegend) or biotin anti-mouse CD183 (CXCR3) (Biolegend) and APC-Streptavidin (BD Biosciences). Intracellular cytokine staining was performed using a Cytofix/Cytoperm kit (BD). PE-rat anti-mouse IL17A (BD Biosciences), PE/Cy7 anti-mouse IFN $\gamma$ (Biolegend) were used to detect the cytokines. Data was collected on an LSR II (BD Biosciences), and analyzed using FACS DIVA software (BD).

\section{Fluorescence Activated Cell Sorting}

Samples were prepared as described above and stained with V500-rat anti mouse CD4 (BD Biosciences), PerCP/Cy5.5 CD11b (Biolegend), PerCP/Cy5.5 antimouse $\mathrm{CD} 8 \alpha$ (Biolegend), and either APC anti-mouse CD196 (CCR6) (Biolegend) or Biotin anti-mouse CD183 (CXCR3) (Biolegend) and APC-Streptavidin (BD Biosciences). Cells were sorted on a FACSVantage/Diva cell sorter (BD Biosciences).

\section{Quantitative Real-Time Reverse Transcriptase- PCR assay} Total RNA was purified using TRIzol RNA isolation reagent (Invitrogen Life Technologies) according to the manufacturer's protocol for whole tissue RNA extraction. One $\mu$ g of RNA from each spinal cord sample was incubated with Moloney murine leukemia virus RT (Invitrogen Life Technologies) according to the manufacturer's protocol, using random hexamer primers. Quantitative RealTime Reverse Transcriptase- PCR assay (Quantitative RTPCR) were performed using ABI Prism 7300 Sequence Detection Systems (Applied Biosystems, Foster City, CA). Quantitative RT-PCR was performed for IRF7, CCL2, CXCl10, TNF- $\alpha$, IL-1 $\beta$, IFN $\gamma$, IL17 and CD3, using primers and probes as described previously $[8,18]$. 18s rRNA primers and probes (Applied Biosystems) were used as an endogenous control to account for differences in the extraction and RT of total RNA [8]. Each reaction was performed in $25 \mu \mathrm{l}$ with TaqMan $2 \times$ Universal PCR Master Mix (Applied Biosystems), undiluted cDNA, primers, TaqMan probe, and $2 \times$ filtered sterile milliQ water. For all genes, PCR conditions were 2 minute at $50^{\circ} \mathrm{C}, 10$ minutes at $95^{\circ} \mathrm{C}$ followed by 40 cycles each consisting of 15 seconds at $95^{\circ} \mathrm{C}$ and 1 minute at $60^{\circ} \mathrm{C}$. To determine the relative RNA levels within the samples, standard curves for the PCR were prepared using cDNA from a reference sample and making fourfold serial dilutions. Relative expression values were then calculated by dividing the expression level of the target gene by the expression level of $18 \mathrm{~s}$ rRNA.

\section{Statistical analysis}

Data were analyzed by nonparametric, Mann-Whitney $t$ test using GraphPad Prism software (GraphPad Software Inc., San Diego, California, USA). A p value $<0.05$ was considered to be statistically significant. Data are presented as Mean \pm SEM.

\section{Results}

\section{Upregulation of IRF7 gene expression in EAE}

IRF7 gene expression was measured in spinal cords from WT mice that had been immunized with MOGp35-55 + CFA. The results from three experiments are combined in Figure 1 and 1 show that induction of EAE leads to increased IRF7 gene expression. In addition the up-regulation of IRF7 mRNA correlated with the clinical score (Figure 1A). Consistent with the well-known widespread expression of Type I IFN and its response elements, as well as with previous studies $[7,8,16]$, we found expression of IRF7 mRNA by Th1 and Th17 CD4+ T cells, and by macrophages and microglia (additional file 1 and Figure 1B). IRF7 gene expression increased in CD45dimCD11b+ microglia during the course of EAE nearly reaching the levels seen in CD45highCD11b+ myeloid cells infiltrating the CNS (Figure 1B).

\section{IRF7-deficient mice develop more severe EAE compared} with WT

To assess the role of IRF7 in EAE, we immunized IRF7deficient mice with MOG in CFA with pertussis toxin, a 


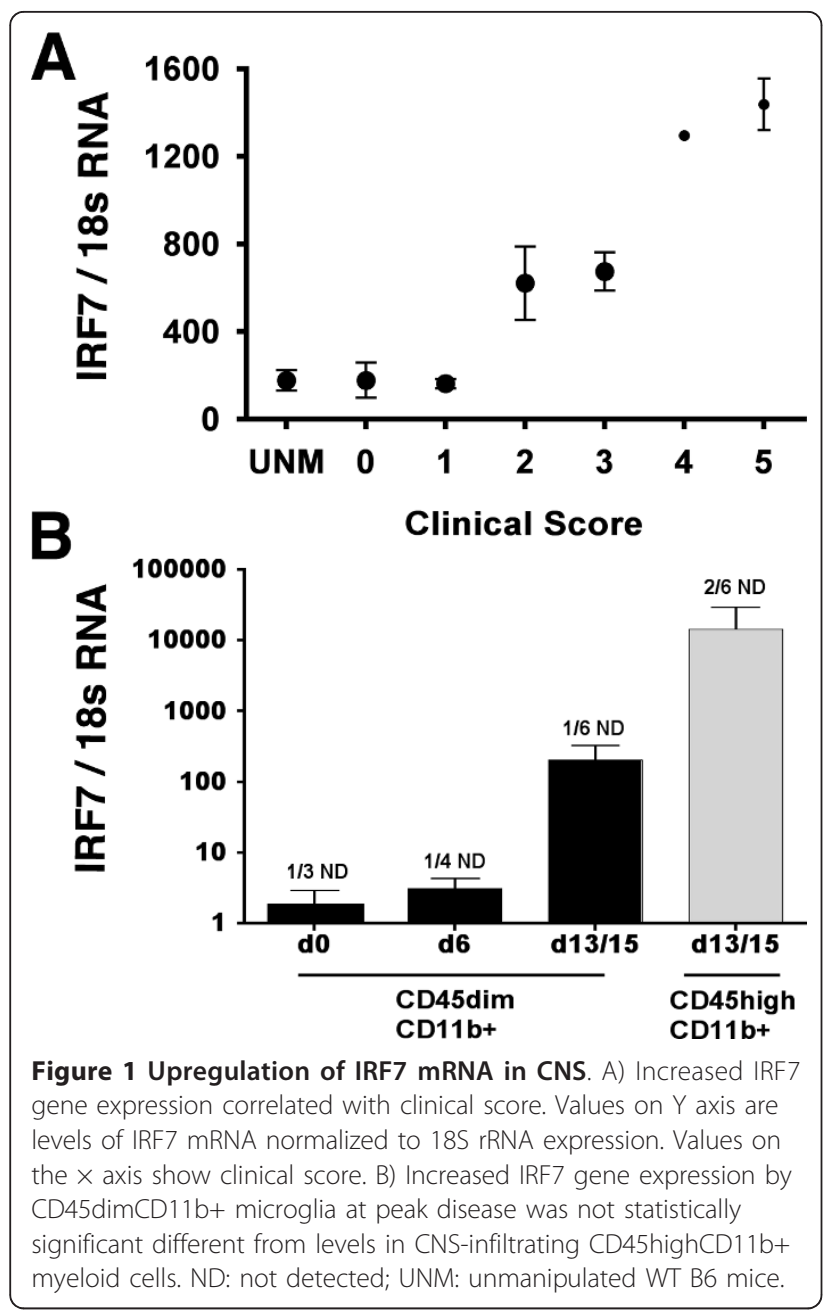

standard protocol for the induction of EAE. In four independent experiments, the mean time of disease onset was not significantly different between WT $(12.99 \pm 1.0$ day) and IRF7-KO $(12.07 \pm 0.7$ day $)$ (Table 1). However, the incidence of EAE differed, being 29/39 (74\%) versus $28 / 30(93 \%)$ in WT and IRF7-KO mice, respectively (Table 1). Nearly half of the animals with EAE were euthanized at grade 5 in the IRF7-KO group, compared to only $4 / 29$ of those in the WT group (Table 1). Whereas the number of mice with EAE that did not achieve grade 3 was almost $50 \%$ in WT groups, less than a quarter of IRF7-KO mice failed to reach this level of severity (Table 1). Results from one experiment are shown as mean clinical scores in Figure 2A. IRF7 deficient mice developed significantly more severe EAE symptoms (Figure 2A). The need for ethical reasons to euthanize mice with severe disease disallowed study of disease progression in severely affected animals and may have obscured a statistically significant difference in severity. Increased disease severity was paralleled by significantly greater loss of whole body weight (Figure 2B).

\section{Increased immune cell entry into IRF7-deficient CNS}

We then investigated the effect of IRF7 gene deletion on the infiltration of cells into the CNS. Flow cytometric analysis showed the clinical score of both WT and IRF7-deficient mice was correlated to the number of infiltrating blood-derived cells, as expected. Bloodderived $\mathrm{CD} 45^{\text {high }} \mathrm{CD} 11 \mathrm{~b}^{+}$macrophages were discriminated by their higher level of expression of CD45 from CNS-resident microglia (Figure 3A). The total number of infiltrating $\mathrm{CD} 45^{\text {high }} \mathrm{CD} 11 \mathrm{~b}^{+}$macrophages $(\mathrm{p}<0.022$, Figure 3A, D), CD4+ $(\mathrm{p}<0.022$, Figure $3 \mathrm{~B}, \mathrm{E})$ and $\mathrm{CD} 8$ $+\mathrm{T}$ cells $(\mathrm{p}<0.014$, Figure $3 \mathrm{C}, \mathrm{F})$ was higher in IRF7KO compared with WT CNS with more severe EAE.

\section{IRF7 deficiency affected distribution of infiltrating} immune cells in CNS

Fluorescence microscopy was used to localize infiltrating cells in the CNS. CD3+ T cells were increased in number and more diffusely dispersed in white matter in the spinal cord of IRF7-deficient mice with EAE, compared to the more focal and constrained infiltration pattern in WT spinal cord (Figure 4). In contrast to T cells, there was no apparent effect of IRF7-deficiency on numbers or distribution of GFAP+ astrocytes (Figure 4A, B). We further examined $\mathrm{CD} 3 \varepsilon$, IFN $\gamma$ and IL17 gene expression by quantitative RT-PCR. The content of CD3 $\varepsilon$ and IFN $\gamma$ mRNA was increased in spinal cords from both IRF7deficient and WT mice with EAE, but no significant differences could be measured when CD3 $\varepsilon(\mathrm{p}<0.2086)$ and IFN- $\gamma$ mRNA $(\mathrm{p}<0.0649)$ were compared between IRF-7 deficient and WT mice (Figure 4C, D). In contrast, IL-17 gene expression was higher $(\mathrm{p}<0.0087)$ in IRF7-KO spinal cord than in spinal cords from WT mice with EAE (Figure 4E).

Table 1 Relative incidence, onset, and severity of EAE in IRF7-deficient and control mice

\begin{tabular}{llllll}
\hline & Incidence & Onset (day) & \# mice with EAE that did not reach Grade $\mathbf{3}$ & ${\text { \# mice reaching Grade } \mathbf{5}^{\mathbf{a}}}$ & \# mice showing remission $^{\mathbf{b}}$ \\
\hline Wild-type & $29 / 39$ & $12.99 \pm 1.0$ & $11 / 29$ & $4 / 29$ & $7 / 29$ \\
\hline IRF7-KO & $28 / 30$ & $12.07 \pm 0.7$ & $6 / 28$ & $12 / 28$ & $2 / 28$ \\
\hline
\end{tabular}

a: Progression to Grade 5 was in all cases rapid and resulted in euthanasia before day 18 .

${ }^{b}$ : Reduction in severity of EAE by one grade was defined as remission. 


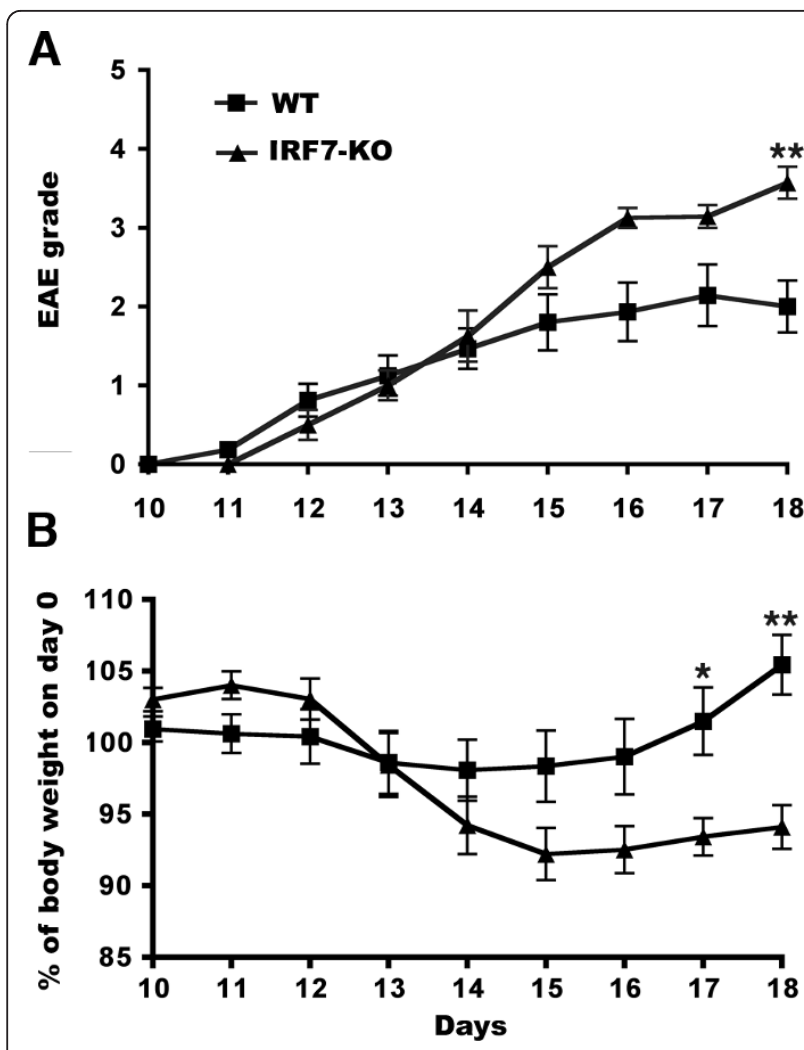

Figure 2 IRF7-KO mice develop more severe EAE. A) Clinical score of mice with EAE. IRF7 deficient mice $(n=8)$ developed more severe EAE than WT B6 control $(n=16)$ as indicated by the asterisk. B) Change in whole body weights as percent of weight one day prior to immunization (Day 0). ${ }^{*} P<0.05,{ }^{* *} p<0.01$.

Increased percentage of CD4+IFN $\gamma+$ T cells in LN of IRF7deficient mice

To further investigate the role of IRF7 on Th1 and Th17 cells during EAE, we measured IFN $\gamma$ and IL17 production by CD4+ T cells from spinal cords and LN. IRF7
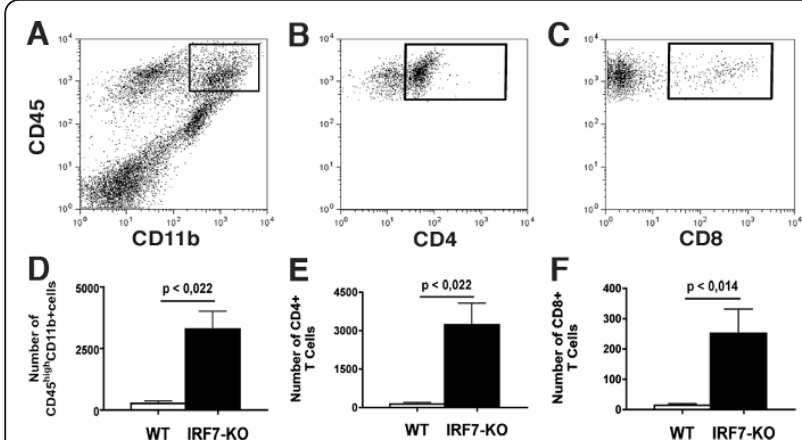

Figure 3 IRF7 deficient mice had more CNS-infiltrating cells. AC) Example of FACS profiles of CNS from IRF7-KO mice with EAE. FACS profiles show $C D 45^{\text {high }} \mathrm{CD} 11 \mathrm{~b}^{+}$macrophages (A), CD4+ T cells (B), and CD8+ T cells (C). IRF7-KO mice $(n=7)$ had more infiltrating CD45 ${ }^{\text {high }} \mathrm{CD}_{11} \mathrm{~b}^{+}$macrophages (D), CD4+ (E) and CD8+ (F) cells in the CNS compared to WT mice $(n=6)$.
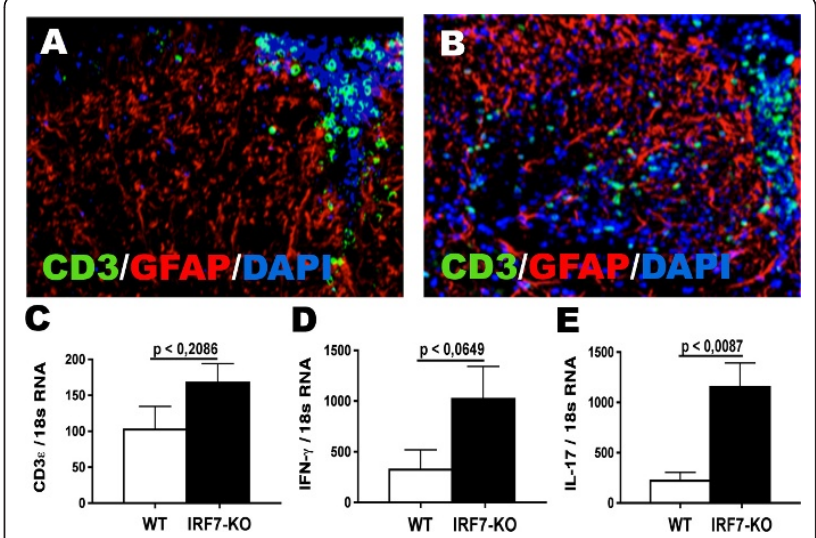

Figure 4 CD3, GFAP, DAPI Immunostaining and quantitative real-time PCR analysis of T cells and related cytokines in IRF7KO and WT mice with EAE. CD3+ T cells were dispersed more diffusely in the spinal cord of IRF7-deficient mice with EAE (B) compared to the more focal infiltration pattern in WT spinal cord (A). IRF7 deficiency had no apparent effect on GFAP+ cells (astrocytes). A-B) original magnification 20×. C-E). CD3 $\varepsilon$ (C), IFN- $\gamma(D)$, and $\mathrm{IL}-17$ (E) gene expression in the CNS of IRF7-deficient ( $n=6-7$ ) and WT mice $(n=5-7)$ were calculated and normalized to 18s rRNA.

deficiency did not affect percentages of $\mathrm{T}$ cells producing these cytokines in spinal cord (not shown). However, lack of IRF7 resulted in an increase $(\mathrm{p}<0.006)$ in the percentage of CD4+IFN $\gamma+$ cells (Figure 5), but not in CD4+IL17+ T cells (not shown) in LN.

Elevated CCL2, CXCL10 and IL-1 $\beta$ expression in IRF7deficient EAE

We next examined whether lack of IRF7 affected the expression of inflammatory mediators that are known to

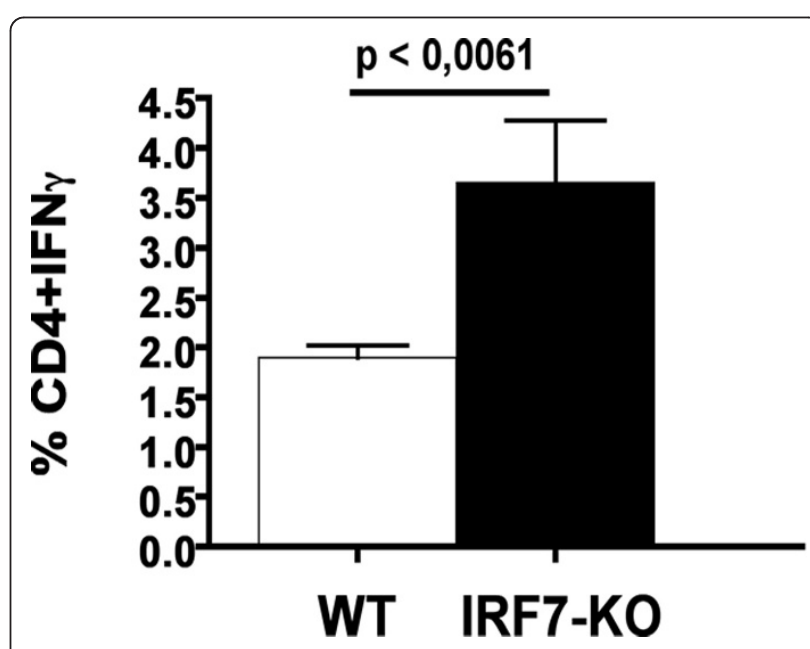

Figure 5 IRF7 deficiency resulted in increased percentage of CD4+IFN $\boldsymbol{\gamma}+\mathrm{T}$ cells in LN. After immunization with MOGp35-55 in CFA, IRF7-KO mice showed a significantly greater percentage of CD4+IFN $\gamma$ cells in LN compared to similarly-immunized WT mice. 
be involved in induction and regulation of EAE. Levels of the chemokines CCL2, CXCL10, and cytokines IL-1 $\beta$ and TNF- $\alpha$ increased in EAE and correlated to clinical severity (not shown). Quantitative RT-PCR analysis showed that the increases in expression of CCL2 ( $\mathrm{p}<$ 0.0176 , Figure 6A) and CXCL10 ( $<<0.0111$, Figure 6B), IL-1 $\beta$ ( $\mathrm{p}<0.0260$, Figure $6 \mathrm{C})$ and TNF- $\alpha(\mathrm{p}<0.0530$, Figure 6D) were higher in IRF7-deficient spinal cord than in spinal cord from WT mice with EAE.

\section{Discussion}

The pathogenesis of MS and its animal models include immune cell activation and their infiltration to the CNS, causing demyelination and axonal damage. The activation of immune cells involves innate receptor signaling [19], that is up-regulated in mice with EAE and modulates pathogenesis of EAE $[20,21]$. The innate receptor signaling that induces type I IFN, involves IRF7 [22]. IRF7 is activated by innate receptor signaling and regulates the induction of type I IFN. Type I IFN signaling further induces IRF7. It has been shown that the level of IFN- $\beta$ in the CNS was increased in mice with EAE [13]. In concordance with this, we show that levels of IRF7 are increased with EAE severity. Thus, the increased IRF7 expression may represent a protective function for IRF7 in EAE.

The mechanism by which type I IFNs regulate CNS inflammation has been shown to include reduction of leukocyte migration to the CNS and inhibition of $\mathrm{T}$ cell responses $[23,24]$. Our findings support the former role.

IFN- $\beta$ has been widely used in treatment of MS, and effects of type I IFN in animal models are generally similar to clinical findings. Oral administration of IFN- $\alpha$ to rats caused reduction of inflammation and

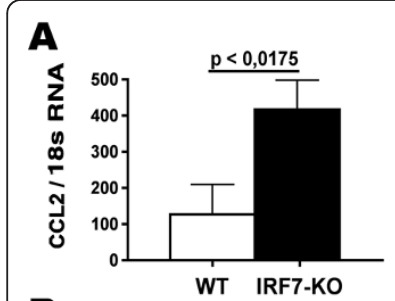

B
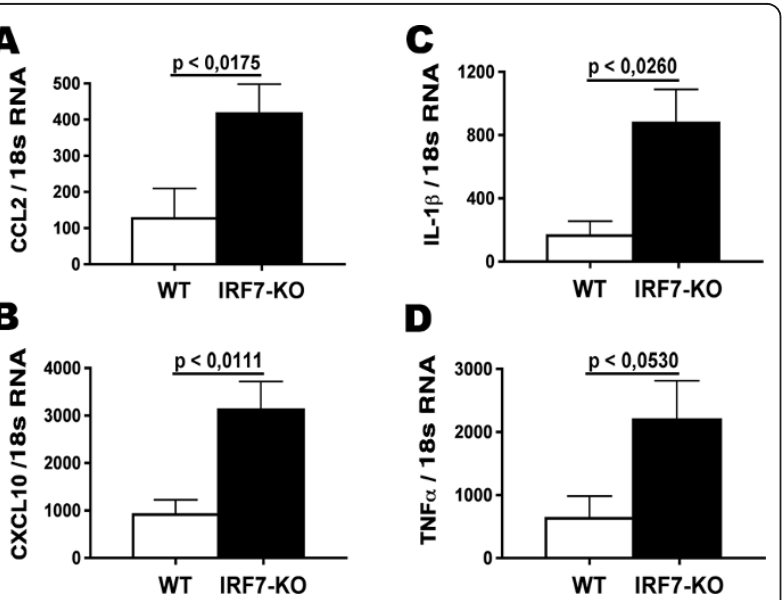

D

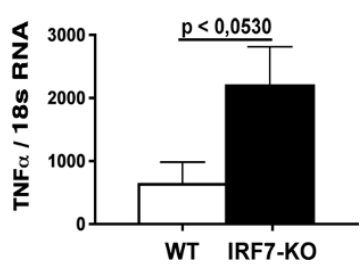

Figure 6 Changes in cytokine and chemokine gene expression in IRF7 deficient $(n=6-7)$ and WT mice $(n=6-7)$. Real-time PCR analysis of CCL2 (A), CXCL10 (B), IL-1 $\beta$ (C) and TNF- $\alpha$ (D) showing these gene expression levels. ameliorated EAE symptoms [23]. Similarly, treatment with IFN- $\beta$ could ameliorate EAE in rats and was associated with a reduction in the number of infiltrating leukocytes to the CNS $[25,26]$. In addition, IFN- $\beta$ deficient mice develop more severe EAE with increased leukocyte infiltration [14]. This was supported by studies in IFNAR deficient mice that likewise showed more severe EAE with increased infiltration $[13,20]$. Here we show that IRF7 deficiency resulted in more severe EAE with higher leukocyte infiltration than WT mice with EAE. Our findings point to IRF7 as a key signaling intermediate in modulation of autoimmune demyelinating disease, and open the possibility that innate signals may also be protective.

Leukocyte infiltration is regulated by chemokines and cytokines and previous studies have shown that CCL2 and CXCL10 play a key role in attracting leukocytes to the CNS in both EAE and after brain injury $[13,27,28]$. In the present study we show that the increase in CCL2 and CXCL10 during EAE was significantly higher in IRF7 deficient mice compared with WT mice. The increased chemokine expression in the CNS might either be secondary to increased entry of peripheral immune cells, which are a potential source of several chemokines and cytokines, or could be due to direct effect of IRF7 on chemokine expression, or to a combination of the two. It has been demonstrated that innate receptor and type I IFN signaling regulate chemokine expression [22,29-31], but whether lack of IRF7 directly leads to increased chemokine and cytokine expression is not known. It has been shown that endogenous IFN- $\beta$ selectively inhibits TNF- $\alpha$, but not IL-1 $\beta$ expression [14], whereas in another study it was shown that IFN- $\beta$ enhanced production of both [32]. It is also shown that deficiency in IFNAR resulted in reduced CXCL10 expression, but had no effect on CCL2 $[8,31]$. The effect of type I IFN signaling on production of chemokine and cytokines seems to depend on context.

However, in line with our observation in this study, Prinz et al., showed that CXCL10 and CCL2 levels in IFNAR-deficient mice increased [13]. CCL2 and CXCL10 chemokines are known to control both degree and pattern of leukocyte entry [33-35], and correspondingly we show that the increased chemokine level was associated with increased and more disseminated infiltration.

Taken together this could suggest that IRF7 regulates leukocyte infiltration through type I IFN regulated chemokine release. Alternatively, regulation could be mediated through IFN-independent mechanisms, by which IRF7 independently inhibits leukocyte migration, for instance by blocking the release of chemokines. IRF7 could also influence leukocyte entry to the CNS through 
mechanisms involving the inhibition of matrix metalloproteinase or adhesion molecules [36-38].

MS is considered to be a $\mathrm{T}$ cell mediated autoimmune disease. It has been shown that IFN- $\gamma$ secreting Th1 and IL-17 secreting Th17 cells play a crucial role in EAE $[39,40]$, although neither cytokine is absolutely required for EAE [41,42]. The ratio of Th17 and Th1 has been reported to be crucial for the localization of infiltration in CNS of mice with EAE [43]. It has been shown that innate receptor induced type I IFN is essential in limiting Th17 development and autoimmune inflammation $[20,44]$. In concordance, we find that IRF7 deficient mice had significantly higher number of $\mathrm{T}$ cells in the CNS compared with WT mice with EAE. Additionally, both IL17 and IFN $\gamma$ were expressed at higher levels in the CNS of IRF7 deficient mice compared with WT. Our findings point to IRF7 as a key signaling intermediate in type I IFN modulation of autoimmune disease.

We used CXCR3 and CCR6 as surrogate markers for Th1 and Th17 respectively to show that IRF7 is expressed by both Th1 and Th17 CD4+ T cells and that IRF7 levels do not change significantly as mice progress through EAE. This suggests that both Th1 and Th17 could be affected by IRF7-deficiency. Consistent with this, both IFN $\gamma$ and IL17 were increased in CNS. Galligan et al., and Guo et al., showed that IFN $\beta$ or IFNAR signaling inhibited Th17 development, and Guo et al., also showed that TRIF signaling inhibited both Th1 and Th17, consistent with our findings $[15,20]$. It also cannot be excluded that enhanced Th1 and Th17 responses in our study reflected altered activity of antigen-presenting cells, since macrophages, dendritic cells and microglia can all express $\mathrm{CD} 11 \mathrm{~b}$ and so were potentially affected by IRF7-KO. Dissection of the relevant cell type (s) whose IRF7 response controlled inflammatory $\mathrm{T}$ cell induction would require lineage-specific knockouts, such as were used by Prinz and colleagues [13]. We then performed intracellular cytokine staining of CD4+ T cells from LN and spinal cords. The percentages of CD4 + IFN $\gamma+$ and CD4+IL17+ T cells in the spinal cords were unaffected by IRF7 deficiency. However, the percentages of CD4+IFN $\gamma+$ cells in the lymph nodes increased in IRF-KO mice. Our data had already shown increased expression of both IFN $\gamma$ and IL17 in CNS of IRF7 KO mice, though only to significance for IL17. Modulation of Th1 development and IFN $\gamma$ production by Type I IFN has been described by others $[14,45,46]$. The differences in data obtained from intracellular cytokine staining and cytokine message measured in spinal cords could be attributed to the fact that IL17 message detected by PCR in IRF7-KO could originate from sources other than $\mathrm{T}$ cells in the CNS.

EAE also involves gamma-delta $\mathrm{T}$ cells which do not express either CD4 or CD8 [47], and we can speculate that the lack of correspondence that we have shown between CD3 mRNA and CD4 and CD8 numbers may indicate differential effect of Type I IFN signaling on this subset. Alternatively it is possible that CD3 mRNA levels were downregulated in activated IRF7-KO T cells.

Genetic factors contribute to an individual's risk of developing autoimmune disease. The transcription factors IRF5 and IRF8 that are involved in both innate receptor and type I IFN signaling pathways have been identified as risk genes associated with MS $[48,49]$. IRF7 itself has been identified as a risk factor for human systemic lupus erythematosus [50] and has been shown to be co-regulated along with IRF8 in MS [49]. In the present study, we demonstrate functional significance of IRF7 in regulation of EAE. This would argue for loss of function as the probable basis for IRF7 as a risk factor in MS, although such association or its mechanism has not been established.

\section{Conclusion}

Administration of IFN- $\beta$ as therapy is beneficial for MS and it needs to be considered whether and how endogenous IFN I signaling would also contribute to disease modulation. Our results point to IRF7 as controlling the immunoregulatory effects of IFN- $\beta$ and potentially acting to direct both innate and IFNAR signals towards regulatory pathways. This opens possibilities for a precise targeting of signaling pathways in MS. Future studies on treatment of MS may therefore consider IRF7 as therapeutic target.

\section{Additional material}

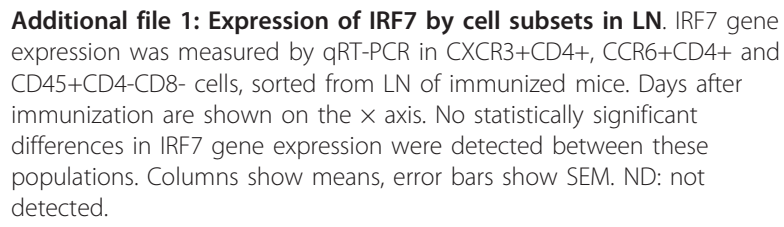

Additional file 1: Expression of IRF7 by cell subsets in LN. IRF7 gene expression was measured by qRT-PCR in CXCR3+CD4+, CCR6+CD4+ and CD45+CD4-CD8- cells, sorted from LN of immunized mice. Days after immunization are shown on the $x$ axis. No statistically significant differences in IRF7 gene expression were detected between these populations. Columns show means, error bars show SEM. ND: not detected.

\section{List of abbreviations}

APC: allophycocyanin; CNS: central nervous system; EAE: experimental autoimmune encephalomyelitis; IRF7: Interferon regulatory factor 7 ; IFN: Interferon; IL-1 $\beta$ : interleukin-1 $\beta$; IFNAR: type I interferon receptor; LN: lymph node; MOG: myelin oligodendrocyte glycoprotein; MS: multiple sclerosis; PE: phycoerythrin.

\section{Acknowledgements}

We are grateful to Dina Dræby, Pia Nyborg Nielsen and Mie Rytz Hansen for their excellent technical support.

\section{Authors' contributions}

TO and RK conceived and designed the experiments. MS, ML, JTM and RK performed the experiments. MS, ML, JTM, RK and TO analyzed the data. MS, ML, JTM, RK and TO wrote the paper. All authors have read and approved the final manuscript. 


\section{Competing interests}

The authors declare that they have no competing interests.

Received: 5 July 2011 Accepted: 23 December 2011

Published: 23 December 2011

\section{References}

1. Steinman L: Multiple sclerosis: a coordinated immunological attack against myelin in the central nervous system. Cell 1996, 85:299-302.

2. Weiner HL: The challenge of multiple sclerosis: how do we cure a chronic heterogeneous disease? Ann Neurol 2009, 65:239-248.

3. Gold R, Linington C, Lassmann H: Understanding pathogenesis and therapy of multiple sclerosis via animal models: 70 years of merits and culprits in experimental autoimmune encephalomyelitis research. Brain 2006, 129:1953-1971.

4. Panitch HS: Early treatment trials with interferon beta in multiple sclerosis. Mult Scler 1995, 1(Suppl 1):S17-21.

5. Giovannoni G, Miller DH: Multiple sclerosis and its treatment. J R Coll Physicians Lond 1999, 33:315-322.

6. Schindler C, Levy DE, Decker T: JAK-STAT signaling: from interferons to cytokines. J Biol Chem 2007, 282:20059-20063.

7. Ousman SS, Wang J, Campbell IL: Differential regulation of interferon regulatory factor (IRF)-7 and IRF-9 gene expression in the central nervous system during viral infection. J Virol 2005, 79:7514-7527.

8. Khorooshi R, Owens T: Injury-Induced Type I IFN Signaling Regulates Inflammatory Responses in the Central Nervous System. J Immunol 2010.

9. Seth RB, Sun L, Chen ZJ: Antiviral innate immunity pathways. Cell Res 2006, 16:141-147.

10. Honda K, Yanai H, Takaoka A, Taniguchi T: Regulation of the type I IFN induction: a current view. Int Immunol 2005, 17:1367-1378

11. Honda K, Yanai H, Negishi H, Asagiri M, Sato M, Mizutani T, Shimada N, Ohba Y, Takaoka A, Yoshida N, Taniguchi T: IRF-7 is the master regulator of type-I interferon-dependent immune responses. Nature 2005, 434:772-777.

12. Benveniste EN, Qin H: Type I interferons as anti-inflammatory mediators. SCi STKE 2007, 2007:pe70

13. Prinz M, Schmidt H, Mildner A, Knobeloch KP, Hanisch UK, Raasch J, Merkler D, Detje C, Gutcher I, Mages J, Lang R, Martin R, Gold R, Becher B, Bruck W, Kalinke U: Distinct and nonredundant in vivo functions of IFNAR on myeloid cells limit autoimmunity in the central nervous system. Immunity 2008, 28:675-686.

14. Teige I, Treschow A, Teige A, Mattsson R, Navikas V, Leanderson T, Holmdahl R, Issazadeh-Navikas S: IFN-beta gene deletion leads to augmented and chronic demyelinating experimental autoimmune encephalomyelitis. J Immunol 2003, 170:4776-4784.

15. Galligan CL, Pennell LM, Murooka TI, Baig E, Majchrzak-Kita B, Rahbar R, Fish EN: Interferon-beta is a key regulator of proinflammatory events in experimental autoimmune encephalomyelitis. Mult Scler 2010 16:1458-1473.

16. Delhaye S, Paul S, Blakqori G, Minet M, Weber F, Staeheli P, Michiels T: Neurons produce type I interferon during viral encephalitis. Proc Natl Acad Sci USA 2006, 103:7835-7840.

17. Jelinsky SA, Miyashiro JS, Saraf KA, Tunkey C, Reddy P, Newcombe J, Oestreicher JL, Brown E, Trepicchio WL, Leonard JP, Marusic S: Exploiting genotypic differences to identify genes important for EAE development. J Neurol Sci 2005, 239:81-93.

18. Toft-Hansen $H$, Fuchtbauer $L$, Owens T: Inhibition of reactive astrocytosis in established experimental autoimmune encephalomyelitis favors infiltration by myeloid cells over T cells and enhances severity of disease. Glia 2011, 59:166-176.

19. Takeda K, Akira S: Toll-like receptors in innate immunity. Int Immunol 2005, 17:1-14

20. Guo B, Chang EY, Cheng G: The type I IFN induction pathway constrains Th17-mediated autoimmune inflammation in mice. J Clin Invest 2008, 118:1680-1690

21. Prinz M, Garbe F, Schmidt H, Mildner A, Gutcher I, Wolter K, Piesche M, Schroers R, Weiss E, Kirschning CJ, Rochford CD, Bruck W, Becher B: Innate immunity mediated by TLR9 modulates pathogenicity in an animal model of multiple sclerosis. J Clin Invest 2006, 116:456-464.
22. Honda K, Takaoka A, Taniguchi T: Type I interferon [corrected] gene induction by the interferon regulatory factor family of transcription factors. Immunity 2006, 25:349-360.

23. Brod SA, Scott M, Burns DK, Phillips JT: Modification of acute experimental autoimmune encephalomyelitis in the Lewis rat by oral administration of type 1 interferons. J Interferon Cytokine Res 1995, 15:115-122.

24. Kozovska ME, Hong J, Zang YC, Li S, Rivera VM, Killian JM, Zhang JZ: Interferon beta induces T-helper 2 immune deviation in MS. Neurology 1999, 53:1692-1697.

25. Ruuls SR, de Labie MC, Weber KS, Botman CA, Groenestein RJ, Dijkstra CD, Olsson T, van der Meide PH: The length of treatment determines whether IFN-beta prevents or aggravates experimental autoimmune encephalomyelitis in Lewis rats. J Immunol 1996, 157:5721-5731.

26. van der Meide PH, de Labie MC, Ruuls SR, Groenestein RJ, Botman CA Olsson T, Dijkstra CD: Discontinuation of treatment with IFN-beta leads to exacerbation of experimental autoimmune encephalomyelitis in Lewis rats. Rapid reversal of the antiproliferative activity of IFN-beta and excessive expansion of autoreactive $T$ cells as disease promoting mechanisms. J Neuroimmunol 1998, 84:14-23.

27. Babcock AA, Kuziel WA, Rivest $\mathrm{S}$, Owens $\mathrm{T}$ : Chemokine expression by glial cells directs leukocytes to sites of axonal injury in the CNS. J NeurosCi 2003, 23:7922-7930.

28. Khorooshi R, Babcock AA, Owens T: NF-kappaB-driven STAT2 and CCL2 expression in astrocytes in response to brain injury. J Immunol 2008, 181:7284-7291.

29. Aravalli RN, Peterson PK, Lokensgard JR: Toll-like receptors in defense and damage of the central nervous system. J Neuroimmune Pharmacol 2007, 2:297-312.

30. Lande R, Giacomini E, Grassi T, Remoli ME, Iona E, Miettinen M, Julkunen I, Coccia EM: IFN-alpha beta released by Mycobacterium tuberculosisinfected human dendritic cells induces the expression of CXCL10: selective recruitment of NK and activated T cells. J Immunol 2003, 170:1174-1182

31. Zhai Y, Qiao B, Gao F, Shen X, Vardanian A, Busuttil RW, KupiecWeglinski JW: Type I, but not type II, interferon is critical in liver injury induced after ischemia and reperfusion. Hepatology 2008, 47:199-206.

32. Jin S, Kawanokuchi J, Mizuno T, Wang J, Sonobe Y, Takeuchi H, Suzumura A: Interferon-beta is neuroprotective against the toxicity induced by activated microglia. Brain Res 2007, 1179:140-146.

33. Muller M, Carter SL, Hofer MJ, Manders P, Getts DR, Getts MT, Dreykluft A, Lu B, Gerard C, King NJ, Campbell IL: CXCR3 signaling reduces the severity of experimental autoimmune encephalomyelitis by controlling the parenchymal distribution of effector and regulatory $\mathrm{T}$ cells in the central nervous system. J Immunol 2007, 179:2774-2786.

34. Huang DR, Wang J, Kivisakk P, Rollins BJ, Ransohoff RM: Absence of monocyte chemoattractant protein 1 in mice leads to decreased local macrophage recruitment and antigen-specific $\mathrm{T}$ helper cell type 1 immune response in experimental autoimmune encephalomyelitis. J Exp Med 2001, 193:713-726.

35. Christensen JE, de Lemos C, Moos T, Christensen JP, Thomsen AR: CXCL10 is the key ligand for CXCR3 on CD8+ effector T cells involved in immune surveillance of the lymphocytic choriomeningitis virus-infected central nervous system. J Immunol 2006, 176:4235-4243.

36. Floris S, Ruuls SR, Wierinckx A, van der Pol SM, Dopp E, van der Meide PH Dijkstra CD, De Vries HE: Interferon-beta directly influences monocyte infiltration into the central nervous system. J Neuroimmunol 2002 127:69-79

37. Stuve $\mathrm{O}$, Chabot $\mathrm{S}$, Jung $\mathrm{SS}$, Williams G, Yong WW: Chemokine-enhanced migration of human peripheral blood mononuclear cells is antagonized by interferon beta- $1 \mathrm{~b}$ through an effect on matrix metalloproteinase- 9 . $J$ Neuroimmunol 1997, 80:38-46.

38. Liuzzi GM, Latronico T, Fasano A, Carlone G, Riccio P: Interferon-beta inhibits the expression of metalloproteinases in rat glial cell cultures: implications for multiple sclerosis pathogenesis and treatment. Mult Scler 2004, 10:290-297.

39. Gutcher I, Becher B: APC-derived cytokines and T cell polarization in autoimmune inflammation. J Clin Invest 2007, 117:1119-1127.

40. Steinman $L$ : A brief history of $T(H) 17$, the first major revision in the $T(H)$ $1 / T(H) 2$ hypothesis of T cell-mediated tissue damage. Nat Med 2007, 13:139-145. 
41. Haak S, Croxford AL, Kreymborg K, Heppner FL, Pouly S, Becher B, Waisman A: IL-17A and IL-17F do not contribute vitally to autoimmune neuro-inflammation in mice. J Clin Invest 2009, 119:61-69.

42. Komiyama Y, Nakae S, Matsuki T, Nambu A, Ishigame H, Kakuta S, Sudo K, Iwakura Y: IL-17 plays an important role in the development of experimental autoimmune encephalomyelitis. J Immunol 2006, 177:566-573.

43. Stromnes IM, Cerretti LM, Liggitt D, Harris RA, Goverman JM: Differential regulation of central nervous system autoimmunity by $T(H) 1$ and $T(H) 17$ cells. Nat Med 2008, 14:337-342.

44. Sweeney CM, Lonergan R, Basdeo SA, Kinsella K, Dungan LS, Higgins SC, Kelly PJ, Costelloe L, Tubridy N, Mills KH, Fletcher JM: IL-27 mediates the response to IFN-beta therapy in multiple sclerosis patients by inhibiting Th17 cells. Brain Behav Immun 2011.

45. McRae BL, Semnani RT, Hayes MP, van Seventer GA: Type I IFNs inhibit human dendritic cell IL-12 production and Th1 cell development. J Immunol 1998, 160:4298-4304.

46. Axtell RC, de Jong BA, Boniface $K$, van der Voort LF, Bhat $R$, De Sarno $P$, Naves R, Han M, Zhong F, Castellanos JG, Mair R, Christakos A, Kolkowitz I, Katz L, Killestein J, Polman CH, de Waal Malefyt R, Steinman L, Raman C: T helper type 1 and 17 cells determine efficacy of interferon-beta in multiple sclerosis and experimental encephalomyelitis. Nat Med 2010, 16:406-412.

47. Sutton CE, Lalor SJ, Sweeney CM, Brereton CF, Lavelle EC, Mills KH: Interleukin-1 and IL-23 induce innate IL-17 production from gammadelta T cells, amplifying Th17 responses and autoimmunity. Immunity 2009, 31:331-341.

48. Kristjansdottir G, Sandling JK, Bonetti A, Roos IM, Milani L, Wang C, Gustafsdottir SM, Sigurdsson S, Lundmark A, Tienari PJ, Koivisto K, Elovaara I, Pirttila T, Reunanen M, Peltonen L, Saarela J, Hillert J, Olsson T, Landegren U, Alcina A, Fernandez O, Leyva L, Guerrero M, Lucas M, Izquierdo G, Matesanz F, Syvanen AC: Interferon regulatory factor 5 (IRF5) gene variants are associated with multiple sclerosis in three distinct populations. J Med Genet 2008, 45:362-369.

49. De Jager PL, Jia X, Wang J, de Bakker PI, Ottoboni L, Aggarwal NT, Piccio L, Raychaudhuri S, Tran D, Aubin C, Briskin R, Romano S, Baranzini SE, McCauley JL, Pericak-Vance MA, Haines JL, Gibson RA, Naeglin Y, Uitdehaag B, Matthews PM, Kappos L, Polman C, McArdle WL, Strachan DP, Evans D, Cross AH, Daly MJ, Compston A, Sawcer SJ, Weiner HL, Hauser SL, Hafler DA, Oksenberg JR: Meta-analysis of genome scans and replication identify CD6, IRF8 and TNFRSF1A as new multiple sclerosis susceptibility loci. Nat Genet 2009, 41:776-782.

50. Fu Q, Zhao J, Qian X, Wong JL, Kaufman KM, Yu CY, Mok MY, Harley JB, Guthridge JM, Song YW, Cho SK, Bae SC, Grossman JM, Hahn BH, Arnett FC, Shen N, Tsao BP: Association of a functional IRF7 variant with systemic lupus erythematosus. Arthritis Rheum 2011, 63:749-754.

doi:10.1186/1742-2094-8-181

Cite this article as: Salem et al:: Interferon regulatory factor-7 modulates experimental autoimmune encephalomyelitis in mice. Journal of

Neuroinflammation 2011 8:181.

\section{Submit your next manuscript to BioMed Central and take full advantage of:}

- Convenient online submission

- Thorough peer review

- No space constraints or color figure charges

- Immediate publication on acceptance

- Inclusion in PubMed, CAS, Scopus and Google Scholar

- Research which is freely available for redistribution

Submit your manuscript at www.biomedcentral.com/submit 